Artigos

\title{
Vida programada: 0 imbricamento ser humano-máquina e a ideologia da técnica no capitalismo contemporâneo
}

\author{
Edemilson Paranál
}

Márcio Felipe Salles Medeiros²

Resumo: Propondo uma dialética programador-programado como metáfora para pensar a estruturação do poder tecnopolítico nas formações sociais contemporâneas, o presente artigo discute o imbricamento ser humano-máquina em sistemas sóciotécnicos, no tocante às transformações recentes no modo de produção capitalista - regime de acumulação flexível, pós-fordista -, em consonância com o quadro ideológico a estas relacionado. Com isso, pretende-se lançar novas questões para o debate em torno do ciborgue no início no Século XXI a partir de um encontro entre perspectivas micro e macrossociológicas de análise.

Palavras-chave: capitalismo; técnica; ideologia; programação; ciborgue.

Programmed life: the overlapping human-machine and the ideology of technique in contemporary capitalism

1 Heterônimo de Edemilson Cruz Santana Junior - Programa de Pós-Graduação em Sociologia - Universidade de Brasília (UnB) - Brasília - Brasil - edemilsonparana@gmail.com.

2 Programa de Pós-Graduação em Sociologia - Universidade de Brasília (UnB) - Bolsista CNPq - Brasília Brasil - medeiros.mfs@gmail.com. 
Abstract: Proposing a programmer-programmed dialectic as a metaphor to think the structuring of techno-political power in contemporary social formations, the following paper discusses the overlapping human-machine in socio-technical systems regarding recent changes in the capitalist mode of production - flexible or post-fordist regime of accumulation - in line with the ideological panorama related to it. It is intended to introduce new issues into the debate around the cyborg in the early twenty-first century from a meeting between micro and macro-sociological perspectives of analysis.

Keywords: Capitalism; technique; Ideology; programming; cyborg.

\section{Teorias do Ciborgue e leitura do capitalismo contemporâneo: um encontro necessário}

É possível observar no desenvolvimento técnico-científico recente uma direção estrutural ou tendência sistêmica, um leitmotiv, em suma? Onde se origina e para onde caminha o avanço tecnológico no início do Século XXI?

Em diálogo com a recepção de certos conceitos da biologia, a alguns pareceria razoável pensar na evolução técnica como um processo autopoético (Maturana; Varela, 1997), sem direção ou propósito pré-estabelecidos ou, de modo distinto, como um sistema de transmissão de informações, de entropia crescente, porém, limitada em seu desenvolvimento (Wiener, 1950). No entanto, é difícil negar - sob pena de cedermos a teleologias utópicas ou distópicas que, no limite, encontram-se na ideia de tecnologia como um tipo qualquer de deus ex machina - que tal desenvolvimento, como atividade humana que é, encontra-se emaranhado na imensa teia de contextos, relações e disputas sócio-históricas que, de modo inescapável, terminam, em suas incontáveis possibilidades, por condicioná-lo. Como se sabe, este é um postulado sustentado por inúmeros estudos em diferentes tradições das sociologias do Conhecimento, da Ciência e da Tecnologia.

Que a ciência e a tecnologia devem ser compreendidas a partir de sua conjuntura e particularidades sócio-históricas, e que guardam, desse modo, conteúdo social, parece ter se tornado ponto pacífico, difícil de ser refutado, ${ }^{3}$ ao

3 Se atualmente tal acordo está vinculado, em especial, ao profícuo desenvolvimento e consolidação dos chamados Estudos Sociais da Ciência e Tecnologia (ESCT), que aprofunda e radicaliza em distintas vias essa proposição a partir de diferentes aproximações do relativismo teórico-epistemológico, cumpre apontar que, em suas origens, autores marxistas ou diretamente inspirados por quadros de análise marxianos figuram entre os precursores da Sociologia da Ciência e, de modo correlato, das primeiras teses sobre o "condicionamento social" da prática científica e tecnológica, tomadas em seu sentido mais amplo, e aqui lidas a partir de suas dinâmicas sócio-históricas de classe, em relação à produção social. 
menos no âmbito das disciplinas acima mencionadas. Caberia, então, partindo desse acordo, nos perguntarmos, secundariamente, e em termos mais amplos, sobre como se configura, em linhas gerais, o dito "social" que compõe e define, em última instância, tal conteúdo. Aí, evidentemente, reside uma instigante e praticamente interminável polêmica que marca o debate sociológico contemporâneo em suas dimensões epistemológica, teórica e metodológica, não nos cabendo, dadas as limitações deste trabalho, revisá-la e criticá-la em profundidade. De modo mais limitado, cumpre apontarmos a compreensão particular que informa este artigo, nas reflexões a que se propõe.

É que para nós, em sociedades capitalistas globalizadas - estruturadas, no tocante à reprodução de sua vida material, a partir da exploração do trabalho produtivo como pressuposto da acumulação e valorização de capital em suas múltiplas formas e expressões -, ignorar a materialidade das relações de poder, controle e condicionamento nas dinâmicas de produção, circulação e consumo de artefatos técnicos a estas vinculadas poderia significar o desenho de um quadro no mínimo parcial a respeito do que caracteriza enquanto tal o desenvolvimento tecnológico contemporaneamente, bem como suas potencialidades, desdobramentos e limitações.

Sob o pretexto de uma reflexão atenta às novas formas e possibilidades do social consonante às tecnologias do imaterial/cognitivo, e ancorados em diferentes aportes teórico-metodológicos de alcance microssociológico, muitos autores (Haraway, 1997; Gray, 2002; Clark, 2003; 2011) têm estabelecido relações analíticas variadas envolvendo elementos fenomenológicos, discursivos e interacionais (inseridos ou não no quadro de coletividades ampliadas e macroarticuladas) a fim de compreender a dinâmica atual das sociedades contemporâneas. Tal retomada direta, indireta ou lateral de distintas expressões e formas de individualismo metodológico, e mesmo sua radicalização a partir de novas propostas epistemológicas, deixa escapar um conjunto de forças de direcionamento estrutural que não podem ser visualizadas a partir de uma topologia epistemológica fundamentalmente microrrelacional. É em torno da natureza dessas "forças", ou tendências macrossociais, que objetivamos apresentar alguns questionamentos neste trabalho.

Ao lançarmos olhar para as transformações pelas quais tem passado o modo de produção capitalista em escala global, especialmente a partir dos últimos

Destaque, nesse particular, entre outros, para os trabalhos de Mannheim (1976), Hessen (2009) e Zilzel (2000). Tomada em sua generalidade, essa proposição dificilmente encontrará oposição mesmo em autores localizados em outras posições neste debate como Merton (1970) e Bourdieu (1983). 
quarenta anos, é possível observar, em conformidade com o rápido avanço e penetração da economia de mercado em escala mundial, um importante movimento - com diferentes configurações e desdobramentos nos centros e periferias do sistema-mundo (Arrighi, 1994; Wallerstein, 2011) - de grande ampliação da liberdade para a acumulação e circulação de capital financeiro, embasada na virada política, ideológica e econômica, e sustentada na configuração de um novo quadro institucional-regulatório, ao qual convencionou-se chamar neoliberalismo (Harvey, 2005).

Com algumas de suas origens verificáveis, do ponto de vista econômico, na queda das taxas de lucratividade (ou mesmo queda nas expectativas de crescimento de tais taxas de retorno) nas economias centrais, no contexto de esgotamento do capitalismo de bem-estar do pós-guerra, a erosão do regime keynesiano-fordista de regulação, especialmente a partir da crise do petróleo (1973), aponta para a composição do que tem sido definido na literatura econômica como regime de acumulação com dominância da valorização financeira (Chesnais, 1996, 1998, 2005) ou regime de acumulação flexível (Harvey, 1992, 2005, 2008); cenário em que as finanças, liberadas de grande parte de seus constrangimentos anteriores e, portanto, habilitadas a produzir e fazer circular capital fictício ${ }^{4}$ em montantes antes inimagináveis por meio de uma infinidade de novos instrumentos financeiros, passam a dirigir uma reorganização entre os diferentes setores da economia, dispondo-os em relação ao ganho financeiro.

Assim, transformações de grande monta, como a reestruturação produtiva, vinculada à revolução técnico-científica dos últimos quarenta anos, a desespacialização e descentralização territorial dos processos produtivos (que termina por apontar para a desindustrialização em vários países, e a consequente industrialização de outros), transformações na divisão internacional do trabalho e na estrutura administrativa das empresas, a flexibilização e reconfiguração das cadeias globais de produção, entre outras mudanças, configuram novas tendências que encontram nas tecnologias de conectividade uma de suas mais importantes bases operativas de funcionamento e expansão. 
Muito indica haver, dessa forma, mais do que uma mera coincidência histórica entre o acelerado desenvolvimento das tecnologias de informação e comunicação e as mudanças estruturais pelas quais tem passado a economia mundial nas últimas quatro décadas (abertura, liberalização e integração dos mercados, interconectividade, ampliação da circulação de bens, serviços e pessoas etc.). Entre o desenvolvimento das tecnologias da informação e comunicação - que permitem descontar tempo no espaço, e espaço no tempo - e o intento dos agentes econômicos em descontar o futuro no presente em busca de ganhos crescentes nos mercados financeiros há, nos parece, para além de certo paralelismo, uma intrigante afinidade.

O que esses "encontros" apontam no âmbito das tecnologias de imbricamento ser humano-máquina? De que modo sua compreensão pode nos ajudar a lançar outros olhares e novas questões em relação ao estatuto do ciborgue no início do Século XXI?

Já em meados do Século XIX, Karl Marx (2013b) descrevia n'O Capital a tendência do desenvolvimento técnico em promover economia de trabalho vivo, aumentar a produtividade e, com isso, derrubar custos de produção, garantindo a seus possuidores/desenvolvedores vantagens no sistema concorrencial (superlucros) e, secundariamente, por meio deste, centralização e concentração de capital nas mãos de cada vez menos capitalistas. Se essa tendência - que encontra correlato no aumento crescente da produção de mercadorias e, portanto, de seu consumo acelerado (impulsionado pela "fabricação" constante de novos valores de uso e de troca) - aprofunda-se desde então, é verdade que esta se desenvolve atualmente em outro patamar de sofisticação e complexidade.

Para citar um exemplo característico dessa nova realidade, grande parte das negociações de compra e venda de moedas, papéis e instrumentos nos mercados financeiros (capazes de influenciar diretamente, em muitas dimensões, o destino de economias em todo o planeta) é hoje realizada automaticamente por meio de "robôs" de investimento (Mackenzie, D.; Beunza, D.; Millo, Y.; Pardo-Guerra, J. P, 2012; Parana, 2016) - modelos matemáticos, algoritmos de compra e venda de ativos, administrados com o auxílio de redes neurais e inteligência artificial - na velocidade de mili e até microsegundos. Nos mercados estadunidenses, a taxa de penetração dos chamados Algorithimic Traders e High Frequency Traders já é de cerca de 70\% de todas as negociações (The Government Office for Science, London, 2012). No Brasil, esse percentual já alcança $40 \%$ de tudo que é negociado na única bolsa de valores do país (Paraná, 2016). Cabos de fibra ótica, redes de comunicação de alta velocidade, e computação de alta 
performance compõem a base operativa sem a qual este grande sistema não poderia funcionar.

Para além da vinculação direta com um processo particular (ideológico) de racionalização das sociedades ocidentais modernas, amplamente discutido em clássicos como Max Weber (1994), além de inúmeros integrantes do que veio a ser conhecido como Marxismo Ocidental (Anderson, 1989) como Georg Lukács (2003), Theodor Adorno e Max Horkheimer (1988), Herbert Marcuse (1979), Jurgen Habermas (1994), bem como Antonio Gramsci (1999) e Louis Althusser (2001), e sintetizada com especial clareza no tocante à sua expressão mais recente em Frederic Jameson (1997) e David Harvey (1992), o desenvolvimento técnico-científico contemporâneo, que tem na cibernética e na microrrobótica conectadas em rede sua coluna vertebral, desenha outro platô de sofisticação material e ideológica para as dinâmicas de controle e administração da vida sócio-produtiva.

Os ciberconflitos e os aparatos de vigilantismo, espionagem e militarização da rede mundial de computadores, que vieram a público por meio das revelações do Wikileaks de Julian Assange e dos vazamentos de informações do ex-funcionário da NSA Edward Snowden (Goldfarb, 2015), colocam em perspectiva a necessidade de refletirmos o avanço técnico-informacional a partir de tais desdobramentos. Para onde caminha, do ponto de vista político, a configuração de nossas relações com tais artefatos técnicos e com os demais seres humanos em sociedade? Quais conteúdos sociais guardam tais objetos enquanto bens de consumo e valores de uso?

A partir da dialética programador-programado como uma metáfora para pensar a estruturação do poder técnico-político nas formações sociais contemporâneas, discutimos o imbricamento ser humano-máquina em sistemas sóciotécnicos no tocante às transformações recentes no modo de produção capitalista - regime de acumulação flexível, pós-fordista - buscando, dessa maneira, um novo olhar crítico para a problemática do ciborgue no início do Século XXI.

Esperamos, por meio deste esforço, animado por certo hibridismo entre perspectivas que caminharam por trajetórias relativamente distintas até aqui, apontar, no fértil encontro de miradas e apontamentos micro e macrossociológicos, para além de potencialidades emancipatórias e contra-hegemônicas - já amplamente discutidas em inúmeros trabalhos como Castells (1999), Shirky (2008), Levy (1995, 1999) -, mas, sobretudo, os dilemas e constrangimentos postos à liberdade política em nosso tempo, problematizando, a partir desse ponto de vista, os trabalhos que têm sido produzidos a respeito do ciborgue.

Se o exercício guarda pertinência em especial no que se refere à problematização do ciborgue, cumpre notar que a articulação de uma leitura crítica do 
desenvolvimento tecnológico em termos das transformações no modo de produção capitalista (e vice-versa) não é propriamente uma novidade. Para descrever e organizar conceitualmente as mudanças pelas quais passam as sociedades na virada do Século XX e início do Século XXI, vários autores têm sugerido termos e conceitos que dialogam com tais transformações das forças produtivas, como capitalismo digital (Schiller, 2000), capitalismo virtual (Dawson; Foster, 1998), capitalismo de alta tecnologia (Haug, 2003), capitalismo informático (Fitzpatrick, 2002), capitalismo comunicativo (Dean, 2005), capitalismo cognitivo (Negri, 2003; 2008) e capitalismo informacional (Castells, 1999), por exemplo. Sem nos aprofundarmos nesse rico debate, nos somamos, ainda que em uma dimensão reduzida de tal discussão, ao intento de lançar luz às relações entre desenvolvimento tecnológico e modo de produção capitalista ou, mais amplamente, entre tecnologia e novas possibilidades de configuração social; tema que tem atraído a atenção de inúmeros estudiosos.

\section{Em torno do conceito de ciborgue}

De modo a adentrarmos ao núcleo de nossas proposições, faz-se necessário antes apresentarmos e discutirmos o conceito de ciborgue.

A definição de ciborgue, segundo Haraway (1991), está relacionada a uma série de hibridismos. O primeiro e mais conhecido diz respeito a superação do binômio homem-máquina. $\mathrm{O}$ desdobramento lógico deste hibridismo é o questionamento da concepção de natureza humana. ${ }^{5}$

A natureza humana, segundo a concepção do ciborgue (Clark, 2003; Haraway, 1991), não está dissociada de seu entorno. A forma pela qual nos relacionamos com o mundo, por meio de instrumentos técnicos, altera a nossa percepção e mesmo nossa estrutura física. Mais adaptados ao entorno (ambiente), vemos ampliar nossas possibilidades de alteração do mundo a nossa volta. Há algum tempo trabalhos antropológicos têm discutido a evolução humana como um processo bio-cultural (Geertz, 2001). Diante disto, alguns questionamentos são importantes: é realmente possível dizer o que é inerente ao humano e o que pertence a seu entorno? E mesmo que fosse possível separar o homem de seu entorno, ao analisarmos a ação humana, esta separação é produtiva para compreendê-la?

5 Cumpre mencionar a vinculação de tal discussão ao contexto mais amplo dos debates a respeito do humanismo x anti-humanismo em suas dimensões filosófica, teórica e política. Apesar deste ter se tornado um debate incontornável no que se refere à temática do ciborgue e imbricamento ser humano-máquina, as limitações característica deste trabalho não nos possibilita aprofundá-lo com o rigor necessário. Para uma discussão a respeito do anti-humanismo teórico em Niklas Luhmann e Louis Althusser ver Silva; Paraná; Pimenta (2015). 
Ao admitirmos a tese de que os elementos associados a materialidade (mundo concreto dado por objetos e ferramentas), elementos sociais (culturas e instituições) e elementos pessoa-sujeito (dimensões cognitivas e orgânicas em sentido amplo) moldam, em conjunto e influenciados uns pelos outros, aquilo que somos, conclui-se que, de certa forma, sempre fomos ciborgues. Assim, a concepção de "humanidade pura", na qual uma unidade física e cognitiva humana (ou "indivíduo") é compreendida como uma espécie de ilha no meio do mundo, perde sentido na busca pela compreensão a respeito de nosso estágio atual de desenvolvimento societal.

Obviamente, o entorno deste "indivíduo" nem sempre foi o mesmo. Para compreender o ciborgue, pois, é necessário compreender a história desta forma de configuração de "indivíduo" e daquilo que o cerca, para, assim, contextualizá-lo devidamente.

Para começar, é certo que esta forma de organização do "indivíduo" só é possível por meio da plasticidade humana (Clark, 2003, 2011), que está associada a adaptabilidade de seu corpo e cérebro às diferentes situações que são colocadas à sua disposição. Sob tal ponto de vista, o corpo humano não é um, mas vários que podem ser transmutados bastando estímulos externos (Serres, 2004). Podemos verificar isto ao analisarmos uma atividade física qualquer, como uma arte marcial, por exemplo. Ao iniciarmos a atividade, falta-nos tônus muscular, alongamento e coordenação motora, que com o treino são incorporados e naturalizados na atividade, gerando uma cadeia de alterações físicas nos músculos, articulações, circulação sanguínea etc.

Além disso, no tocante à cognição, já é conhecida a possibilidade de alteração dos circuitos sinápticos por meio da interação com um novo objeto ou por meio da aquisição de um novo conhecimento. Deste modo, interagimos com o mundo produzindo transformações na paisagem por meio de tecnologias, e este mundo, em sentido inverso, ativa mudanças em nosso organismo, em uma dialética contínua entre o exterior e interior (IHDE, 2009).

A plasticidade humana - que permite sermos alterados por meio da interação com o mundo enquanto nos utilizamos de tais alterações para transformá-lo - é o que nos torna ciborgues (Clark, 2003). Deste modo, e em sentido alargado, o ciborguismo estaria associado até mesmo à construção das primeiras civilizações. ${ }^{6}$

6 Aqui cabe resgatar Marx, n’ O Capital (2013), quando trata da relação metabólica de mútua transformação entre homem e natureza: "Agindo sobre a natureza externa e modificando-a por meio desse movimento, ele [o homem] modifica, ao mesmo tempo, sua própria natureza” (p. 255). Mais à frente (p. 261-2), em nota de rodapé, o autor cita o coronel Torrens, quem, segundo ele, teria descoberto "na pedra 
De outro lado, o ciborguismo demanda outro hibridismo: entre imaginário e realidade (Haraway, 1991), ou seja, ao mesmo tempo que o imaginário é construído, este constructo pode engendrar transformações na própria realidade. No caso do ciborguismo contemporâneo, vinculado, conforme discutiremos à frente, à busca pela "eficiência" e potencialização das capacidades humanas, 0 imaginário ligado à ficção torna-se especialmente importante.?

Cumpre salientar, diante disso, que o imaginário não está dissociado do quadro ideológico em que estamos inseridos e que, dessa forma, compõe o contexto geral em que vivemos. Em última instância, o imaginário está intimamente relacionado aos sentidos, práticas e modos de organização da vida social do qual somos partícipes em atos cotidianos.

O ciborguismo, portanto, embora seja constitutivo de uma característica orgânica - a plasticidade - associada a construções culturais humanas, encontra, ao menos desde meados do Século XIX, um processo de dinamização relacionado à cultura capitalista; processo este que se acelera com especial intensidade a partir do fim do Século XX. O corpo, a cidadania, a afetividade, práticas sexuais e toda sorte de relações sociais são agora perpassadas por tecnologias e estão imbricadas em relações ciborgues (Sibila, 2002; Gray, 2002; Soares e Medeiros, 2011). Como Haraway (1991) ressalta, o ciborguismo contemporâneo emerge em meio a dissoluções de barreiras, na qual o corpo é dessacralizado como essencialmente "natureza" e pode fundir-se à cultura tecnológica emergente, assim como o imaginário assimila e incorpora essas dissoluções.

Nos termos do capitalismo como modo de organização da vida sócio-produtiva, então, dimensões (ideológicas) vinculadas a dinâmicas de controle, ampliação da eficiência e lucro estão diretamente relacionados ao ciborgue. Tecnologias como computadores e softwares são constantemente atualizadas de modo a agilizar tarefas em busca de eficiência crescente e, por consequência, ampliar a quantidade e capacidade de trabalho (e consumo) realizado pelos indivíduos. As tecnologias que produzem o ciborgue do fim do Século XX

do selvagem a origem do capital": "Na primeira pedra que [o selvagem] arremessa contra a fera que ele persegue, no primeiro varapau que ele pega para arrancar o fruto que sua mão não consegue alcançar, vemos a apropriação de um artigo para o propósito da aquisição de outros e, assim, a origem do capital", R.Torrens, An Essay on the Production of Wealth (Londres, 1821, p.70-1).

7 Filmes, como Star Wars, por exemplo, influenciaram toda uma geração de cientistas e tecnólogos, que hoje buscam desenvolver tecnologias análogas às do filme, temática abordada no documentário "ciência da guerra das estrelas". O documentário foi produzido pelo canal Discovery e compôs uma série de episódios que traziam tecnologias que haviam sido produzidas inspiradas no filme Guerra nas Estrelas (Star Wars). Este debate está diretamente relacionado com a relação entre ficção e produção de realidade, desenvolvida por Heyles (1999). 
(Haraway, 1991; Schneider, 2005), emergem em meio a um contexto capitalista, belicista e patriarcal. Dado não serem artefatos neutros, exógenos ou plenamente autônomos em relação aos seus conteúdos e propósitos sociais, sua utilização não pode se dar, portanto, de modo inocente.

\section{Questões a respeito do estatuto do ciborgue na (pós) modernidade capitalista}

Discutido brevemente o conceito de ciborgue, cumpre localizá-lo no quadro de referência do capitalismo contemporâneo, nos termos de suas relações sociais de produção e, em íntima correlação com estas, em seus significados e desdobramentos ideológicos.

Ao discutir a Condição Pós-Moderna, Harvey (1992) diagnostica a existência de "algum tipo de relação necessária entre a ascensão de formas culturais pós-modernas, a emergência de modos mais flexíveis de acumulação do capital e um novo ciclo de 'compressão do tempo-espaço' na organização do capitalismo" (p. 8). Ainda que aponte na obra O Capital a disputa em torno do tempo de trabalho (socialmente necessário) entre capitalistas e trabalhadores no interior da fábrica como elemento fundamental para a compreensão dos mecanismos de extração de mais-valor, é amparando-se no Marx (2013) dos Grundrisse, para quem, quanto mais desenvolvido o capital, mais tende à "anulação do espaço através do tempo" em busca de estender suas "trajetórias especiais de circulação" (mercados), que Harvey argumenta que a suposta cumulatividade do progresso tecnológico capitalista, em que inovações adotadas desenham contextos que permitem o surgimento de outras, e assim sucessivamente, se dá justamente na direção da crescente aceleração dos movimentos e processos produtivos ou destrutivos.

Essa aceleração, como superação do espaço através do tempo (e igualmente do tempo através do espaço, conforme é possível verificar nos mercados financeiros contemporaneamente), pode ser observada desde o fim do feudalismo e início do período colonial, com especial ênfase a partir do advento da industrialização e "modernização" das sociedades. É, desse modo, um fenômeno constitutivo da cognição operacional, cada vez mais sofisticada, da própria dinâmica de reprodução do capital, sempre levada a acelerar-se em todas as suas fases, de modo a expandir suas fronteiras de valorização. A esse fato está relacionado, na visão do autor, um conjunto de deslocamentos nas formas de relação e representação do mundo por parte dos indivíduos, visto tempo e espaço serem categorias fundamentais para a organização - material, cultural e cognitiva - das sociedades. 
Tal interpretação pode ser extraída também, em certa medida, das considerações de Marx e Engels (2006) presentes n’ O manifesto do partido comunista. Conforme aponta Musse (2010), em seu excurso sobre a passagem do feudalismo para o capitalismo, os autores descrevem três tendências expansivas fundamentais do capitalismo: uma expansão imanente, definida pela constante revolução dos meios de produção e das técnicas de trabalho; uma expansão intensiva, que engloba outras esferas da sociedade para além da esfera da produção; e, por fim, uma terceira, extensiva, responsável por ampliar o alcance do capitalismo, ao submeter os segmentos pré-capitalistas interna e externamente. $O$ desdobramento de todas essas tendências, em consonância com a consolidação dos processos de acumulação de capital, é justamente uma aceleração tanto das percepções do tempo, bem como a "integração" de aéreas e regiões da Terra antes inexploradas.

Há, desse modo, conforme argumenta Harvey (1992), um vínculo constitutivo entre o conjunto de transformações que articulam a implementação de novas formas organizacionais e novas tecnologias que aceleraram os tempos de produção, troca e consumo; o crescimento do setor de serviços, o predomínio do curto-prazo como temporalidade hegemônica na tomada de decisões nas esferas produtiva, política e sociocultural; as crescentes fusões e aquisições (centralização e concentração de capitais); a busca por vantagens relativas de localização e a deslocalização industrial; o rápido avanço de tecnologias de comunicação e informação; e, em correlação com estas, o crescimento e ganho de proeminência dos mercados financeiros nos termos da chamada "financeirização" das economias.

Tal tendência globalizante à aceleração, consubstanciada na economia de trabalho vivo e na expansão das fronteiras para acumulação e valorização de capital, apresenta-se no "curto-prazismo" da dominância financeira e na crescente flexibilização da produção em relação aos seus constrangimentos sócio-políticos (controle do trabalho humano), materiais (obtenção de matérias primas) e técnicos (inovações produtivas), intimamente vinculada à prática tecnológica contemporânea - como num encontro de suas dimensões estruturais com suas expressões ideológicas.

A esse respeito, cumpre resgatarmos as formulações da escola althusseriana que, em meados da década de 60, notabilizou-se por, a partir de releituras de Marx, em aproximações críticas com a psicanálise e a linguística, reconfigurar a definição de ideologia, deslocando-a da acepção de "falsa consciência" (vinculada até então às teorias da reificação e da alienação) para uma compreensão ancorada no modo de como os indivíduos, vivendo em sociedade, representam-na no âmbito de sua relação com o mundo. 
A partir de tal conceito de ideologia, entendida ao mesmo tempo como material e imaginária, porque vinculada à prática da vida cotidiana, caberia pensar que todas as sociedades - inclusive as pré e/ou pós-capitalistas - são perpassadas por ideologias múltiplas, compreendidas aqui, mais uma vez, em relação à inescapável necessidade de representação do mundo, como necessário processo de redução de sua complexidade por meio de estruturas mentais, no âmbito de indivíduos situados em relações sociais objetivas. A ideologia não seria, assim, apenas uma negatividade, um não-saber, mas um saber específico, quer seja um saber imaginário sobre o mundo. Por outro lado, tais representações adquirem existência material por meio de práticas, comportamentos e instituições (aparelhos), ao mesmo tempo em que, por meio destas, fundam e reproduzem elas próprias tais ideologias.

Nessa direção, urge retomarmos aqui, num encontro certamente inusitado, mas não por isso menos produtivo, o hibridismo entre imaginário e realidade, nos termos de Haraway (1991), em partes compatível, ao nosso ver, com tal concepção de ideologia, por meio do qual voltamos ao debate a respeito dos hibridismos característicos do ciborgue.

A partir dessa conceituação de ideologia - que vincula a representação do mundo às formas cotidianas de vida em consonância com as relações sociais de produção - abundam exemplos na direção da problemática que nos empenhamos em apontar, qual seja: a circunscrição dos desenvolvimentos contemporâneos do ciborgue em termos das limitações desenhadas no quadro do capitalismo em sua fase avançada.

Boltanski e Chiapello (2009), ao discutirem o "novo espírito do capitalismo", falam da dissolução das fronteiras entre trabalho e consumo, entre tempo profissional e privado no âmbito de forças que celebram indivíduos "interativos", operadores constantes de tecnologias de informação e comunicação. Na mesma direção, Brennan (2003) aponta para uma "biodesregulamentação" dos seres humanos diante da tentativa de superação das incompatibilidades entre o funcionamento temporal dos mercados desregulamentados e as limitações físicas dos seres humanos, obrigados a lidar com tais demandas e exigências de funcionamento.

Seguindo esse raciocínio, na esteira do que define como cibertariado ( $c y$ bertariat), Ursula Huws (2003) aponta a intensificação das jornadas de trabalho mediante o desvanecimento das fronteiras entre público e privado na exploração dos "info-trabalhadores" flexíveis (operadores de telemarketing, programadores de software, designers, gestores de informação, entre outros) que, a partir de plataformas de informação e conectividade, são levados a estarem disponíveis às demandas de seus empregadores a qualquer momento. No âmbito desse quadro, o padrão de regulação de tais relações de trabalho tende à 
informalização, flexibilização, subcontratação, "pejotização" e outras formas de autoexploração do trabalho que negam ou transferem para o trabalhador o custo dos encargos e direitos trabalhistas. Assim,

Apesar do significativo avanço tecnológico encontrado (que poderia possibilitar, em escala mundial, uma real redução da jornada ou do tempo de trabalho), pode-se presenciar em vários países, como a Inglaterra e o Japão, para citar países do centro do sistema, uma política de prolongamento da jornada de trabalho. A Inglaterra tem a maior jornada de trabalho dentre os países da União Europeia, e o Japão, se já não bastasse sua histórica jornada prolongada de trabalho, vem tentando, por meio de propostas do governo e dos empresários, aumentá-la ainda mais, como receituário para a saída da crise (Antunes, 2005: 33-34).

Ademais, explorando as potencialidades desses mesmos avanços tecnológicos, bancos, empresas aéreas e inúmeros outros setores têm incentivado o autoatendimento de seus clientes - um recurso para a economia de trabalho apresentado como processo de "autonomização do indivíduo", financiado, no entanto, pela autoexploração do próprio consumidor (que trabalha, ou economiza trabalho, enquanto consome).

No ensaio 24/7: Capitalismo Tardio e os fins do sono, Crary (2014) reúne um conjunto de pesquisas e desenvolvimentos da indústria bélica estadunidense, realizados por meio de parcerias de grandes empresas com agências estatais, para apontar a busca pelo "soldado sem sono", capaz de lutar dias e noites sem interrupção em missões de combate.

A pesquisa sobre privação do sono deve ser entendida como parte de uma busca por soldados cujas capacidades físicas se aproximarão cada vez mais das funcionalidades e aparatos e redes não humanos. O complexo científico-militar tem se dedicado ao desenvolvimento de formas de "cognição ampliada" que prometem aprimorar a interação entre homem e máquina. Simultaneamente, as Forças Armadas têm financiado diversas outras áreas de pesquisa do cérebro, incluindo o desenvolvimento de uma droga contra o medo (Crary, 2014: 12-13).

A tais desenvolvimentos o autor relaciona outros avanços das indústrias bioquímica e farmacêutica em consonância com a busca por aumento de performance nos termos de uma "cultura do 24/7", na qual a economia global tenciona um funcionamento ininterrupto dos mercados. O sono, argumenta, seria uma das últimas barreiras a serem ultrapassadas pela acumulação capitalista. 
Isso porque, no sistema econômico global, dependente da produção e consumo ininterruptos, o ócio e, especialmente, o sono, tomados economicamente como tempo inativo e improdutivo, representam limites a sua necessária expansão; daí a busca por, além de soldados, trabalhadores e consumidores "sem sono". A tais desenvolvimentos estaria vinculada ainda a demanda por reconfigurações, não raro destrutivas, dos ciclos de vida, regeneração e sobrevivência dos ecossistemas naturais, explorados produtivamente numa espécie de encontro entre degradação humana e ambiental.

Na direção das teses de Harvey sobre a aceleração das dinâmicas de funcionamento da vida social em consonância com os ciclos de expansão da circulação, acumulação e valorização de capital, Crary (ibid.) argumenta que a busca por um funcionamento $24 / 7$ faz-se presente na lógica sistêmica do capitalismo ao menos desde os idos do Século XIX, quando começa a tomar forma em sua configuração industrial moderna. ${ }^{8}$

Dentre as muitas condições, que já estariam em nosso horizonte, citadas pelo autor para a objetivação desta "cultura", uma merece especial atenção: a difusão da internet por meio de dispositivos móveis dotados de atualização constante, ao que poderíamos relacionar as redes wireless e a chamada "internet das coisas", com sua "temporalidade ininterrupta" (p. 40). Em meio a várias citações de referências da arte, literatura e cinema presentes no ensaio (corroborando o hibridismo ciborgue entre real e imaginário de Haraway), a citação do romance O círculo, de Dave Eggers, ganha destaque: a ficção trata de uma empresa de mídias sociais gigantesca, cujo objetivo é a propagação de uma ideia de "compartilhamento" a orientar a exposição $24 / 7$ de vidas individuais, abrindo caminho para a vigilância em massa.

Em torno das discussões do que veio a ser conceituado como capitalismo cognitivo, Negri $(2003,2008)$ aponta para o apagamento das fronteiras entre trabalho produtivo e ócio improdutivo no contexto de novas formas de reprodução do valor, mediadas por tecnologias do imaterial e de inteligência coletiva em redes de conexão global. Neste quadro, o fim da privacidade é apontado como tendência face às novas formas de acumulação capitalista dentro e fora das redes de colaboração. Inescapável, aqui, a remissão ao amplo conjunto de práticas panópticas desenvolvidas nos últimos duzentos anos.

8 A este respeito cumpre resgatar o célebre capítulo do Livro I d' O Capital (MARX, 2013) sobre A jornada de trabalho, onde discute a necessidade de as fábricas funcionarem de modo ininterrupto, produzindo longas jornadas de trabalho e o consequente revezamento dos trabalhadores em turnos diurnos e noturnos. 
A vigilância em massa e a exploração econômica de conteúdos produzidos na internet, em especial nos termos de um consentimento ideológico quase celebratório, a incentivar a auto-exposição performática de dados e informações pessoais, igualmente convida à retomada de algumas das teses de Foucault $(1993,1997)$. Os sistemas de disciplinamento típicos das lógicas de biopoder voltados à produção de mais-valor econômico e cultural - apontam, contemporaneamente, para a dimensão ideológica do ciborgue em seus hibridismos múltiplos, especialmente no tocante às injunções entre real e imaginário.

Independentemente de aderirmos ou não a tais abordagens, é patente do ponto de vista empírico o avanço da vigilância da vida pública e privada na internet, como desdobramento, inclusive, de disputas intra e inter corporações, e em suas relações com Estados e cidadãos-consumidores. Mesmo autores que desde as décadas de 1990 e 2000 vêm ressaltando o potencial integrador e emancipatório da rede, como Castells (1999; 2009), já assumem que, paralelamente à expansão da conectividade global, observam-se inúmeros constrangimentos às liberdades políticas coletivas e individuais. A mercantilização da internet fez avançar seu correlato em administração e controle da vida social, fundamento que é dos disciplinamentos necessários à expansão da atividade econômica.

\section{A Dialética programador-programado na produção científica}

O debate a respeito de um possível antagonismo entre programadores e programados remete às críticas elaboradas pelos primeiros movimentos por democracia tecnológica, herdeiros das redes de hackers da contracultura, formadas entre as décadas de 1960 e 1980, nos Estados Unidos (Castells, 1999). Contemporaneamente, tais críticas compõem o núcleo das intervenções de coletivos hackers e, com especial proeminência, dos movimentos em defesa do desenvolvimento e uso de softwares livres. É o caso de Rushkoff (2010), que adentra nessa discussão de modo a criticar posturas passivas em relação à tecnologia. $\mathrm{O}$ livro, ainda que não tenha pretensões acadêmicas, lança ideias sobre a necessidade de empoderamento tecnológico por parte dos indivíduos para "melhor viver" em sociedade. Para isso, torna-se necessária a compreensão de como as tecnologias com as quais interagimos realmente funcionam.

$\mathrm{O}$ autor não avança em questões com as quais nos preocupamos aqui, como ideologia da técnica ou mesmo as lógicas de funcionamento do modo de produção capitalista, mas identifica uma hierarquia típica da atualidade, desenhada em torno daqueles que programam. Em seu argumento, os programadores compõem uma espécie de elite que, detentora ou não de poder econômico, possui a 
capacidade de moldar a estrutura digital, construindo softwares que atendam a seus anseios; fugindo, dessa forma, da passividade característica da maior parte dos usuários. Rushkoff (ibid.) não adentra, no entanto, no mérito do direcionamento estrutural-sistêmico da tecnologia, suas implicações e possíveis efeitos.

Ao discutir os potenciais da evolução "especificamente humana" face aos demais seres vivos, Serres (2003) articula o conceito de exodarwinismo. Por meio dessa formulação, sustenta que as mediações culturais e sócio-técnicas das coletividades humanas na relação com seus ambientes deslocam as leis da seleção natural típicas da evolução biológica. A partir dessa formulação, a "adaptação" se dá com o auxílio de recursos tecnológicos, que possibilitam (re)articular sócio-culturalmente as demandas humanas, abrindo possibilidades de vida em ambientes hostis e permitindo o prolongamento do período de vida útil dos seres humanos. O direcionamento desse exodarwismo desenha-se, dessa forma, por meio da administração "artificial" das formas de vida e de morte.

Na mesma direção segue Haraway (1997) ao apontar a busca pelo controle do código da vida humana por meio do sequenciamento do DNA. A autora nos lembra ainda, que, nessa busca, elementos como as dinâmicas de controle e poder, típicos da sociedade patriarcal, estão embutidos dentro dos modelos de desenvolvimento científico.

Dessa forma, conclui-se que o modo de organização da vida social a qual estamos inseridos interfere diretamente nos rumos do desenvolvimento científico, ao mesmo tempo que aquele é também ativado, em suas transformações, por este. Por meio do desenvolvimento e uso de novas tecnologias - sempre configuradas em íntima relação com tais modos de vida e horizontes civilizacionais - nos é possibilitado reconfigurar as formas de interação com o mundo a nossa volta.

A partir dessa compreensão, Borgmann (1995) diagnostica a crescente supressão de elementos, situações e espaços de sociabilidade presenciais (as quais denomina "coisas focais") face aos novos avanços tecnológicos. Considerando as imbricadas relações entre ciência, empresas e Estados nacionais discutidas em Etzkowitz (2003), caberia apontarmos que tais "supressões" não são arbitrárias, mas estão relacionadas, em última instância, aos horizontes e objetivos dos detentores de poder para mobilizar e aglutinar recursos para a produção tecnológica, o que aqui denominamos programadores.

Muitos são os estudos que apontam a importância da ciência e do desenvolvimento tecnológico para a reprodução do capitalismo, bem como sua vinculação às demandas por este mobilizadas. O avanço tecnológico, desde Marx (2013), pode ser compreendido como uma arma fundamental a ser mobilizada na concorrência entre os capitalistas: ao economizar e potencializar a produtividade 
do trabalho humano, aumentando a intensidade deste, possibilita a exploração de superlucros na dinâmica concorrencial.

Cumpre reforçar, diante de tais observações, que o desenvolvimento técnico-cientifico, tributário do quadro sociocultural em que está inserido, é perpassado e constituído por relações e disputas de poder. O aumento da exploração do trabalho (em suas dimensões absoluta e relativa), para citar um aspecto incontornável dessa reflexão, segue, conforme apontamos, como realidade e tendência diante do avanço das tecnologias de eficiência produtiva. Ao invés de produzir uma nova economia do tempo livre, o novo quadro tem feito, diversamente, aumentar o tempo e a intensidade do trabalho, na direção das demandas de valorização do capital face ao enfraquecimento do poder (social e político) do trabalho.

Assim, e afastando-nos da ideia de que programadores são meros agentes "racionais" munidos de conhecimentos técnicos de programação, buscamos realizar aqui uma livre apropriação da contraposição trabalhada por Rushkoff (2010), a saber, de que há uma hierarquia entre programadores e programados. Entretanto, cumpre enquadrá-la devidamente em suas dimensões estruturais - seja em vinculação às dinâmicas de funcionamento do modo de produção capitalista e suas configurações ideológicas, mas também em relação à própria "estrutura digital", constituída por constrangimentos desenhados a partir dos diferentes modos pelos quais estão dispostas, de modo sobredeterminado, redes, programas, infraestruturas e usuários.

Dessa forma, afastando-nos de uma caracterização nos termos do desenvolvimento de uma dialética linear-simples, como disjuntiva a apontar para uma racionalidade sistêmica (com relação a fins) crescente (como causa/consequência do processo), chamamos atenção, diversamente, para um mecanismo inconsciente, em que uma "irracionalidade" sistêmica contraditória, ainda que funcional, fica patente. Dito de outro modo: não são os atores que ativam, por si mesmos, o movimento de contradições, mas esse movimento que situa e constitui como tais os atores nas disputas em questão, desenhando as margens relativas de sua atuação criativa e criadora.

\section{Considerações finais: em direção a uma dialética programador-programado}

Desenhados alguns vínculos constitutivos entre globalização e capitalismo com dominância da valorização financeira, desenvolvimento das tecnologias da informação e comunicação e a busca por performance e eficiência sócio-técnica para a economia de trabalho, cumpre concluirmos apontando de que modo e 
em quais dimensões tais elementos desembocam nas problematizações referentes ao estatuto contemporâneo do ciborgue.

Materializada na alta performance dos sistemas ser humano-máquina, na vida administrada cognitiva, hormonal e fisiologicamente por meio de tecnologias químicas, biológicas e mecânicas, conectadas em redes de comunicação e mediatização de informações, identidades e performances, o ser humano segue, às custas de cada vez mais trabalho explorado e cada vez menos tempo livre, como em um castigo de Sísifo, a busca por superar a si mesmo e às "limitações" internas e externas de sua pré-história ocidental moderna; de vencer, em suma, as limitações do tempo e do espaço em seu próprio corpo. ${ }^{9}$

Apesar de contabilizar inúmeros avanços no que se refere à medicina, educação, política e práticas sociais outras, o horizonte e produto dessa busca, objetivado na destruição física do planeta, não chega a ser propriamente animador. A reestruturação produtiva, a automatização dos sistemas de mercado, a internalização da vida social em sistemas de informação e vigilância em massa no âmbito da globalização capitalista não deixa mentir suas contradições: no Século XXI, o ser social existe também como ciborgue; imbricado na máquina por meio do trabalho explorado e pelo consumo tecnófilo de mercadorias "mágicas". Os hibridismos entre real e imaginário típicos do ciborgue, apontados por Haraway (1991), não escapam aos seus conteúdos ideológicos.

Que as tendências descritas neste ensaio apontam para o desenvolvimento tecnológico como elemento de economia de trabalho vivo e ampliação de contingentes populacionais considerados desnecessários em termos do capital, intensificação da exploração dos recursos naturais, aceleração dos ciclos de produção e consumo, e, consequentemente, ampliação da exploração do trabalho em relação ao encurtamento dos períodos considerados "improdutivos", esperamos ter ficado evidente. Isso, no entanto, não é suficiente.

A outra face da moeda, ou seja, as dimensões emancipatórias, as novas possibilidades de configuração política e reinvenção contra-hegemônica da vida cotidiana estão longe de serem desprezíveis. O uso e propagação da criptografia, as lutas pelo desenvolvimento e ampliação da penetração de tecnologias e

9 Tal ideal de superação pode ser observado em recentes pesquisas do Pentágono sobre a produção de implantes biônicos para a constituição de "supersoldados". Busca-se, com isso, ampliar a "eficiência" de ações estratégicas de guerra dos EUA, diminuindo o número de baixas com consequente aumento do número de mortes dos inimigos. Sobre tais pesquisas, ver Reardon, S. Pentagon Gambles on Brain Implants, Bionic Limbs and Combat Exoskeletons.

Nature News, 10 jun. 2015. Disponível em: <http://www.scientificamerican.com/article/pentagongambles-on-brain-implants-bionic-limbs-and-combat-exoskeletons/>. Acesso em: 23 jun. 2015. 
softwares livres, e a combatividade e ousadia política dos movimentos de hackers e ciberativistas são exemplos sonoros de tais contratendências.

Aqui, afastando-nos novamente de qualquer teleologia tecnófíla ou tecnófoba, cumpre apresentarmos o desenvolvimento tecnológico nas disputas, contradições e conteúdos sociais, inscritos em seus códigos técnicos (Feenberg, 2005). Se é verdade que tais potencialidades emancipatórias, fartamente discutidas em inúmeros trabalhos a respeito do ciborgue (alguns deles já amplamente conhecidos), não foram o objeto central de nossa discussão, é fato que não podem ser desconsideradas: tais possibilidades de resistências e subversão estão, ainda que em outra chave, no centro deste debate. Até onde se estendem? De que maneira e por quais fatores estão constrangidas?

É, pois, em busca de um balanço que considere suas dimensões positivas e negativas, seus constrangimentos e possibilidades, que defendemos uma leitura do fenômeno sóciotécnico do ciborgue, no encontro de suas estruturas sociais e agências coletivas ou individuais, em suas topologias macro e microssociais, por meio de uma dialética programador-programado.

A partir deste jogo de contradições podemos compreender o ciborgue como configuração em disputa, mas assimétrica em termos de poder; em que, em consonância com formulação de David Noble (2001), "só um dos lados está armado" ou, mais precisamente, um dos lados está melhor armado do que outro.

A metáfora da programação como ato-poder (programador) de configurar a disposição de um sistema/artefato, em termos dos recursos disponíveis em relação aos vários meios e fins, em oposição a seus usos esperados (programados), nos parece ser um recurso analítico potente contra leituras distorcidas, em seu tom otimista, deste fenômeno. Estas acabam por hipertrofiar entusiasticamente as múltiplas e intermináveis apropriações particulares de uso em detrimento de seus constrangimentos estruturais, que estão longe de desaparecer, conforme procuramos demostrar. Se é verdade que o programado em questão encontra certa margem de resistência em seus usos e apropriações criativas, parece certo que o programador, ao desenvolver e controlar as normas e "protocolos" tem, ainda que não onipotente, posição privilegiada ao definir os limites e constrangimentos a essa ação, em consonância com seus objetivos-funções (latentes ou manifestos). De que modo tais contradições conformam o ciborgue em suas potencialidades e limitações?

Tal analogia, como metáfora, poderia ser mobilizada até mesmo para a releitura de outras contradições sociais, dentre as quais, para citar um exemplo, a clássica capital x trabalho: o capital a programar a operação do trabalho que, em seus usos e dispositivos, busca a ele resistir criativamente, ensejando disputas e desdobramentos múltiplos. 
Trata-se, pois, nada mais do que articular, em relação às condições presentes, tais investigações a partir da leitura dos conflitos em tela, bem como das dimensões materiais de poder - mesmo em esferas que, em um primeiro olhar, pareceriam as mais abstratas e abertas à inventividade sem constrangimentos, como a das tecnologias do imaterial: a construção de softwares, arquitetura de redes, simulações e realidades virtuais, robótica, entre outras.

Se recorrer a uma dialética programador-programado pode ser produtivo em uma conjuntura em que a organização e administração da vida em sistemas sóciotécnicos-informacionais parece ser crescente, torna-se fundamental compreendermos as limitações desse recurso analítico: é evidente que os sistemas, em suas complexidades, estão para muito além de uma mera contraposição dual. Novamente, o conjunto de suas múltiplas contradições sobredeterminadas, em distintas configurações, deve ser investigado com rigor em seus arranjos específicos. Defendemos, no entanto, que um olhar voltado para as dinâmicas de controle e poder em seu interior tem muito a oferecer em termos qualitativos, contribuindo para o desenho de quadros mais realistas em seus aspectos teóricos e políticos.

Caberia, assim, em cada caso, avaliar de que modo, em suas múltiplas configurações conjunturais, os sistemas, redes e artefatos situam-se, contrapõem-se ou mesmo imbricam-se em termos das disputas entre programadores e programados e, adicionalmente, de que modo tais disputas condicionam e/ou são condicionadas por seus conteúdos sociais nos termos de suas possibilidades ou limitações de reinvenção e criação social e política.

\section{Referências}

ADORNO, T.; HORKHEIMER, M. Dialética do Esclarecimento. Rio de Janeiro: Zahar, 1988. ALTHUSSER, L. Ideologia e aparelhos ideológicos de estado. 8. ed. Rio de Janeiro: Graal, 2001. ANDERSON, P. Considerações sobre o Marxismo Ocidental. 2. ed. São Paulo: Brasiliense, 1989. ANTUNES, R. Os sentidos do trabalho: ensaio sobre a afirmação e a negação do trabalho. São Paulo: Boitempo editorial, 2005.

ARRIGHI, G. The long twentieth century: money, power, and the origins of our times. Londres and New York: Verso, 1994.

BOLTANSKI, L.; CHIAPELLO, E. O novo espírito do capitalismo. São Paulo: WMF Martins Fontes, 2009.

BORGMANN, A. Information and reality at the turn of the century. Design Issues, v. 11(2), pp. 21-30, 1995.

BOURDIEU, Pierre. O Campo Científico. In: ORTIZ, Renato (org.), Pierre Bourdieu. Sociologia. São Paulo: Ática, 1983. 
BRENNAN, T. Globalization and its Terrors: Daily Life in The West. London: Routledge, 2003.

CASTELLS, M. A sociedade em rede. 10. ed. São Paulo: Paz e Terra, 1999. . Communication Power. New York: Oxford University Press, 2009.

CHESNAIS, F. A mundialização do capital. São Paulo: Xamã. 1996.

. (Org.). A mundialização financeira: gênese, custos e riscos. São Paulo: Xamã. 1998. . (Org.) A finança mundializada: raízes socais e políticas, configuração, consequências. São Paulo: Boitempo, 2005.

CLARK, A. Natural-born cyborgs: minds, technologies, and the future of human intelligence. New York: Oxford University Press, 2003.

Supersizing the Mind: Embodiment, action, and cognitive extension. New York: Oxford University Press, 2011

CRARY, J. 24/7: Capitalismo tardio e os fins do sono. São Paulo: Cosac Naify, 2014.

DAWSON, M.; FOSTER, J., Virtual capitalism, In: MCCHESNEY, R.; WOOD, E.; FOSTER, J. (Ed.), Capitalism and the Information Age. New York, Monthly Review Press, pp. 51-67, 1998.

DEAN, J. Communicative capitalism: circulation and the foreclosure of politics. In: Cultural Politics, v. 1, n. 1, pp. 51-74, 2005.

ETZKOWITZ, H. Hélice Tríplice: Universidade-Indústria-Governo Inovação em Movimento. Porto Alegre: EDIPUCRS, 2009.

FEENBERG, A. Critical Theory of Technology: An Overview. Tailoring Biotechnologies. v. 1, n. 1, p. $47-64,2005$.

FITZPATRICK, T. Critical theory, information society and surveillance technologies. In: Communication and Society, v. 5, n. 3, 2002, pp. 357-78.

FOUCAULT, M. A História da Loucura na Idade Clássica. 5. ed. São Paulo: Perspectiva, 1997. . História da Sexualidade: a vontade de saber. 11. ed. Rio de Janeiro: Graal, 1993.

GEERTZ, C. Nova Luz Sobre a Antropologia. Rio de Janeiro: Jorge Zahar, 2001.

GOLDFARB, R. (ed). After Snowden: privacy, secrecy and security in the information age. New York: Thomas Dunne Books, St. Martin's Press, 2015.

GRAMSCI, A. Cadernos do cárcere. 6 v. Rio de Janeiro: Civilização Brasileira, 1999.

GRAY, C. H. Cyborg Citizen: politics in the posthuman age. New York: Routledge, 2002.

HABERMAS, J. Técnica e ciência como “ideologia”. Lisboa: Edições 70, 1994.

HARAWAY, D. J. Simians, Cyborg and Women: the reinvention of nature. New York: Routledge, 1991. .Modest_Witness@Second_Millennium.FemaleMan@_Meets_OncoMouse ${ }^{\mathrm{Tx}}:$ feminism and technoscience. New York: Routledge, 1997.

HARVEY, D. Condição pós-moderna: uma pesquisa sobre as origens da mudança cultural. São Paulo: Edições Loyola, 1992. . O novo imperialismo. São Paulo: Loyola, 2005. 
. O neoliberalismo: história e implicações. São Paulo: Edições Loyola, 2008.

HAUG, F. High-tech-kapitalismus. Hamburg: Argument, 2003.

HAYLES, N. K. How we became posthuman: virtual bodies in cybernetics, literature and informatics. Chicago: The University of Chicago Press, 1999.

HESSEN, B. The Social and Economic Roots of Newton's Principia. In Freudenthal, G.; Mclaughlin, P. (eds). The Social and Economic Roots of the Scientific Revolution: Texts by Boris Hessen and Henryk Grossmann. Springer: 2009, pp. 41-101.

HUWS, U. The Making of a Cibertariat: Virtual Work in a Real World. New York/London: Monthly Review/The Merlin, 2003.

IHDE, D. Postphenomenology and Technoscience. New York: Suny Press, 2009.

JAMESON, F. Pós-Modernismo: a Lógica Cultural do Capitalismo Tardio. São Paulo: Editora Ática, 1997.

LÉVY, P. As tecnologias da inteligência. Rio de Janeiro: 34 Letras, 1995. . Cibercultura. Rio de Janeiro: Editora 34 Letras, 1999.

LUKÁCS, G. História e consciência de classe: Estudos sobre a dialética marxista. São Paulo: Martins Fontes, 2003.

MACKENZIE, D.; BEUNZA, D.; MILLO, Y.; PARDO-GUERRA, J. P. Drilling Through the Allegheny Mountains: Liquidity, Materiality and High Freanquency Trading. Journal of Cultural Economy, v. 5, n. 3, 2012, pp. 279-296.

MANNHEIM, K. Ideologia e Utopia. Rio de Janeiro: Zahar, 1976.

MARX, K. Grundrisse: manuscritos econômicos 1857-1858. Esboços da crítica da economia política. São Paulo: Boitempo, 2013a.

. O Capital, v. I. São Paulo: Boitempo, 2013b.

. O Capital, v. III, tomo II. São Paulo: Nova Cultural, 1988.

; ENGELS, F. Manifesto do Partido Comunista. São Paulo: Martin Claret, 2006.

MARCUSE, H. A ideologia da sociedade industrial: o homem uni-dimensional. Rio de Janeiro: Zahar, 1979.

MATURANA, H.; VARELA, F. De máquinas e seres vivos. Porto Alegre: Artes Médicas, 1997.

MERTON, Robert K. Sociologia: teoria e estrutura. Miguel Maillet (Trad.). São Paulo: Mestre Jou, 1970.

MUSSE, R. Introdução ao manifesto comunista. In: MARX, K.; ENGELS, F. Manifesto Comunista. São Paulo: Hedra. 2010.

NEGRI, A. Capitalisme cognitif et fin de l'économie politique. In: Multitudes, n. 13, 2003, pp. 197-205.

.; VERCELLONE, C. Le rapport capital / travail dans le capitalisme cognitif. Multitudes, 2008/1 n. 32, pp. 39-50.

NOBLE, D. La loucura de la automatización. Barcelona: Alikornio, 2001. 
PARANÁ, E. A finança digitalizada: capitalismo financeiro e revolução informacional. Florianópolis: Insular, 2016.

RUSHKOFF, Douglas. Program or be Programmed. New York: Or Books, 2010.

SCHILLER, D. Digital capitalism. Cambridge: MIT Press, 2000.

SCHNEIDER, Joseph. Donna Haraway: live theory. New York: Continuum, 2005.

SERRES, M. Hominescências: o começo de uma outra humanidade? Rio de Janeiro: Bertrand Brasil, 2003. . Variações sobre o corpo. Rio de Janeiro: Bertrand Brasil, 2004.

SHIRKY, C. Here Comes Everybody: the power of organizing without organizations. New York: Penguin Books; 2008.

SOARES, H. S. G. e MEDEIROS, M. F. S. Somos Todos Ciborgues: aspectos sociopolíticos do desenvolvimento tecnocientífico. Configurações, v. 8, 2011, pp. 11-32. Disponível em: <https://configuracoes.revues.org/882>. Acesso em: 16 abr. 2017.

THE GOVERNMENT OFFICE FOR SCIENCE. Foresight: the future of computer trading in financial markets. Final Project Report. London, 2012. Disponível em: <https:// www.gov.uk/government/publications/future-of-computer-trading-in-financial-markets-an-international-perspective $>$. Acesso em: 05 jun. 2015.

SIBILA, P. O Homem Pós-Orgânico: Corpo, subjetividade e tecnologias digitais. Rio de Janeiro: Relume Dumará, 2002.

SILVA, L.T.; PARANÁ, E.; PIMENTA, A M. Dois anti-humanismos: a atualidade de uma problemática para a sociologia. 2015. No prelo.

WALLERSTEIN, I. The modern world-system I: Capitalist agriculture and theorigins of the European World-Economy in the Sixteenth Century. California: University of California Press, 2011.

WEBER, M. Economia e sociedade. 3. ed. Brasília: UnB, 1994.

WIENER, N. Cibernética e sociedade: o uso humano de seres humanos. 3 ed. São Paulo: Cultrix [s.d.].

ZILSEL, E. The Sociological Roots of Science. Social Studies of Science, v. 30, n. 6 (Dec., 2000), pp. 935-949.

Recebido em 07/07/2015

Aprovado em 09/09/2016

\section{Como citar este artigo:}

PARANÁ, Edemilson; MEDEIROS,. Márcio Felipe Salles. Vida programada: o imbricamento ser humano-máquina e a ideologia da técnica no capitalismo contemporâneo. Contemporânea - Revista de Sociologia da UFSCar, v. 7, n. 1, jan.- jun. 2017, pp. 223-245. 